\section{Committee on Space Research}

AT its recent meeting in Washington the International Council of Scientific Unions established a Committee on Space Research (COSPAR), with the primary purpose of providing a means whereby the scientific community may use to maximum advantage the possibilities of satellites and space probes for scientific purposes, and exchange the results on a co-operative basis. On November 14 and 15 the Committee on Space Research held its first meeting in the rooms of the Royal Society in London. A constitution was drawn up for approval by the International Council of Scientific Unions, and the following executive committee was elocted: President, Prof. H. C. van de Hulst (International Astronomical Union); Vice-Presidents, Prof. E. K. Fedorov (U.S.S.R. Academy of Sciences, Moscow), Prof. W. Albert Noyes, jun. (University of Rochester, New York); Members, Prof. Maurico Roy (International Union of Theoretical and Applied Mechanics), Prof. H. S. W. Massey (International Union of Pure and Applied Physics).

\section{National Science Foundation Grant for U.S National Observatory}

THE National Science Foundation has allocated 4 million dollars to the Association of Universities for Research in Astronomy, Inc. (AURA), for the construction of a solar telescope. These funds bring to a total of $7,545,000$ dollars the amount that has been allocated so far for the erection and operation of a United States national astronomical observatory on Kitt Peak in the Quinland Mountains of southwestern Arizona (see Nature, 181, $236 ;$ 1958). An additional 1 million dollars has been appropriated by Congress to the National Science Foundation for transfer to the Bureau of Public Roads for construction of a road giving access to the observatory site, which has been leased from the Papago Indians, in whose reservation it lies.

The solar telescope will be equipped with an 80 -in. light-gathering flat at the top of the tower, and a 60 -in. image-forming mirror, with a focal length of $300 \mathrm{ft}$. The instrument will thus be the largest solar telescope in existence, with about twice the focal length of the famous $150-\mathrm{ft}$. tower telescope at Mount Wilson. Stellar instruments at the observatory will consist initially of a 36-in. reflecting telescope to be made by Boller and Chivens, of South P'asadena, California, and an 80-in. high-speed reflecting telescopo by Corning Glass Works, with auxiliary instrumentation.

\section{Lunar Topography: Gift to the University of Manchester}

The Geophysics Research Directorate of the U.S. Air Force, Cambridge (Mass.) Research Conter, entered, as from November 1 of this year, into a contractual arrangement with the University of Manchester (through the European Office of the Air Research and Development Command in Brussels) to support in its Department of Astronomy an extended programme of topographic studies of the Moon. This emphasizes the current need for more accurate information on the heights and dimensions of lunar surface features than we possess to-day. A large part of such data as are now available go back to the work of amateur astronomers of the nineteenth century, and are based on visual measurements the accuracy of which leaves much to be desired. The
Department of Astronomy at Manchester, under Prof. Zdenek Kopal, proposes to increase this accuracy by filming sunrise or sunset over selected lunar regions, and triangulating for the topographical details of the landscape from measurements of the varying lengths of the shadows. This work was actually commenced two years ago by collaboration between the University of Manchester and the Observatoire du Pic-du-Midi in the High Pyrenees, which is well known for its superior seeing, and the photographic work done through the 24-in. refractor of the Observatory by kind permission of the director, Dr. Jean Rösch. The measurements and reductions of all films are to be made at Manchester under the supervision of Dr. Gilbert Fielder.

The ciné technique, pioneered by R. R. McMath, R. M. Petrie and H. E. Sawyer at the University of Michigan in the middle 1930's, has been elaborated in recent years at Manchester and has attained new standards of precision; its application to the Pic-duMidi photographs makes it possible now to distinguish, on the Moon, objects of linear dimensions in excess of $500 \mathrm{yd}$., and altitude differences of the order of $20-30 \mathrm{yd}$. The programme of mapping the entire visible hemisphere of the Moon to this accuracy will probably occupy the Department of Astronomy at Manchester for the next five years, at a total cost of approximately 80,000 dollars.

\section{Rowan Hamilton Bridge}

ON November 13, Mr. Eamon de Valera, Prime Minister of the Republic of Ireland, unveiled a tablet on Broome Bridge at Cabra, Dublin, to commemorate the invention of quaternions. The bridge has now been renamed Rowan Hamilton Bridge. The story of Hamilton and his bridge ranks with those of Archimedes and his bath and of Newton and his apple, as the Provost of Trinity College (Dr. A. J. McConnell) remarked in his speech at the ceremony, and it concerns a man of comparable intelloctual stature. On October 16, 1843, Sir William Rowan Hamilton was walking with his wife along the Royal Canal from Dunsink Observatory to preside at the Council of the Royal Irish Academy when, on coming to Broome Bridge, the long-sought fundamental rules for quaternion algebra flashed upon his mind. Acting upon what he afterwards called an "unphilosophical impulse", he scratched the formulæ on the stonework with his penknife. The same afternoon he gave notice of his intention to read a paper on the subject at the Academy meeting on the following November 13 -hence the date chosen for the unveiling. The tablet was erected by the Council of the Dublin Institute for Advanced Studies, of which the Right Rev. Monsignor P. Browne is chairman. Mr. de Valera, who is himself a mathematician well versed in Hamilton's work, has taken a keen personal interest in the project, which was carried on under the active direction of Prof. F. E. Hackett, chairman of the Governing Board of the School of Theoretical Physics of the Institute.

Hamilton's work on quaternions had widespread influence upon the development of mathematics, especially in America, and it was a pioneering step towards the subsequent far-reaching enlargement of algebra. While it is Hamilton's work in other fields that has had such a profound influence upon the whole form of modern theoretical physics, it would be scarcely possible to find in it, or in the work of any other theorist, anything more apt or evocative for a public memorial than the episode that has now 